University of South Florida

DIGITAL COMMONS

Digital Commons @ University of

@ UNIVERSITY OF SOUTH FLORIDA

South Florida

Communication Faculty Publications

Department of Communication

Fall 2009

\title{
Warm Ideas and Chilling Consequences
}

Arthur P. Bochner

University of South Florida, abochner@usf.edu

Follow this and additional works at: https://digitalcommons.usf.edu/spe_facpub

Part of the Health Communication Commons, and the Interpersonal and Small Group Communication Commons

\section{Scholar Commons Citation}

Bochner, Arthur P., "Warm Ideas and Chilling Consequences" (2009). Communication Faculty Publications. 17.

https://digitalcommons.usf.edu/spe_facpub/17

This Article is brought to you for free and open access by the Department of Communication at Digital Commons @ University of South Florida. It has been accepted for inclusion in Communication Faculty Publications by an authorized administrator of Digital Commons @ University of South Florida. For more information, please contact digitalcommons@usf.edu. 


\title{
Warm Ideas and Chilling Consequences
}

\author{
Arthur P. Bochner
}

\begin{abstract}
In the process of writing my academic memoirs spanning a period of more than thirty-five years, I discovered how crucial the work of Gregory Bateson had been to my life as a teacher, a scholar, and a relational partner. In this paper I celebrate Bateson's charming and incisive ideas about how communication works, his deep reservations about the worship of quantification, and his astute analysis of what is at stake when we make epistemological errors in everyday life. Reviewing a turning point in my academic life-a conference held in 1979, I reaffirm the importance of warm ideas and provide a story that illustrates the potentially monstrous consequences of epistemological error.
\end{abstract}

If you grow up, as we do, with a worship of the quantitative aspect and a minimal attention to the qualitative aspect, I believe you inevitably land yourself in the dilemmas of our civilization.

Gregory Bateson (1981)

But I get back to the fact that the way we are going about things with this enormous emphasis upon the quantitative view and the minimal emphasis upon the patterned view is, I believe, the easiest way of the descent into hell. The surest.

Gregory Bateson (1981)

\section{Prologue}

For the past three summers, I've been sitting in this chair, writing my academic memoirs, trying to make sense of thirty-eight years of academic life. I'm striving to tell the story of how I came to the narrative paradigm of social science inquiry, moving from being immersed in the epistemology of prediction and control to being captivated by meanings and values, desiring to put lived experience in an intelligible frame that can enlighten, emancipate, and alleviate suffering (Bochner, forthcoming). When I began, I had a familiar storyline in mind: I overcome my modest roots (as 
the son of a working-class, Jewish immigrant), work my way through a myriad of contradictions, dilemmas, and setbacks, and transcend my academic socialization (into positivist empiricism). Following a conversion to a new (narrative) paradigm, I achieve peace of mind, wisdom, love, and a re-awakening of spiritual and political conviction. But the more I wrote-or I should say, the more the story wrote me-the more I became aware that I was preoccupied by a struggle to reassure myself that my life as a professor had been meaningful, coherent, and principled. I had to resist the temptation to exaggerate, cope with the fallibility of language, shore up an unreliable memory, and show a healthy respect for the confusion and uncertainty lurking in the corners of my recollection of every phase of my life. I realized that what I was doing was building a relationship to my past, between the selves of my past and me-between there and then and here and now. Like any construction project, this one could not be completed without exertion. There would be more than a little sweat on my brow and more than a few tears running down my cheeks. I couldn't just tell my life, I had to examine it, mull it over, toss it, turn it, squeeze it, embrace it, doubt it, adore it, and trust it in order it to discover, explore, and interpret what I had been thinking, what had inspired me to keep going, and what I really cared about.

Sometime I wonder if I'll ever finish this book. Finishing a life story is akin to finishing a life. Can we ever really know how it will end? Do we want to know?

Nearly every day that I write, I make a new discovery as I look intently on the past and try to figure out what it means. For example, writing this book has allowed me to revisit my mentors. Recently, I discovered how important the work of Gregory Bateson had been to me and I vowed that I would not let his memory die. As far as I am concerned, he was the person who first championed the importance of qualitative inquiry, at least the first one who got through to me.

Bateson anticipated many of the culture wars we've experienced over the past two or three decades. He understood how difficult it can be to introduce change into a rigorously governed, rigidly homeostatic system like academic social science. He would not have been surprised by the backlash against qualitative inquiry. As one of his students, Jay Haley (1963) inscribed as his First Law of Human Relations, "The more change is attempted, the more it is resisted." Haley would have seen the current climate of dispute over the legitimacy of qualitative social science (Denzin, 2009) as a power struggle, not so much a question of what the rules should be, but rather who gets to say what the rules should be (about what counts as legitimate inquiry and methodology).

At the 2009 International Congress of Qualitative Inquiry, I posed a direct question about the usefulness of waging war against the enemies of post-structural, postmodern, autoethnographic, and performative social science. "What do we gain by 
defending ourselves against attacks on our work by the mainstream qualitative community or the scientifically-based research movement?" I asked.

The differences between "them" and us" should be obvious. We don't have the same goals and we don't have the same core beliefs;. Moreover, given the sphere of their influence, they have an investment in perpetuating their own agenda and exercising a politics of exclusion. We aren't going to change their minds and they aren't going to change ours. The only possible outcome is something akin to the old CNN program Crossfire. It would be like trying to hold a constructive dialogue between FOX news and MSNBC? The point I am driving at was made succinctly by Rorty ( 1991, p. 31 ): “. . . we cannot justify our beliefs (in physics, ethics, or any other area) to everybody, but only to those whose beliefs overlap ours to some appropriate extent." There is a limitation to argument. Without some shared premises, we can't convert them from their point of view to ours. Those shared premises do not appear to exist--not now, and not in the foreseeable future.

In this brief paper, I move in a different direction. I return to a turning point in my life, harkening back to my first qualitative publication (Bochner, 1981). Much of the paper is conceptual and methodological, but as a narrativist, I can't resist the temptation of a clinching story, especially a true story with a chilling moral. My goal is to circulate again the idea of epistemological error and its potentially horrifying consequences. This is one of the most important ideas I learned from Gregory Bateson and there's a lesson here I want to pass on to future generations of students of qualitative inquiry across the globe.

\section{Remembering Asilomar}

A graduate student, one of my advisees, comes bounding into my office, grinning from ear to ear, looking as if she were a bubble about to burst.

"I didn't know you were ever that young," Leslie began in a playful, teasing tone.

"What in the world are you talking about?" I replied, puzzled by her question and eager to take the bait.

"I'm taking this course on systems theory with Dr. Steier," she continued. He brought this book to class titled Rigor and Imagination (Wilder-Mott and Weakland, 1981). He'd already assigned some readings from the book, but last night he showed us the photos in it, which were taken at the Asilomar Conference in 1979. We all got a big kick out of them. You looked so hip in that leather vest."

"I suppose you mean that as a compliment," I reply wryly, looking down at my ruffled t-shirt and wrinkled jeans and wondering but not asking why "hip" rarely is used either endearingly or critically to describe a person over 50 . 
"Of course, I do," Leslie assures. "All of us in the class were really amazed to see the glow on the faces of the participants. Everyone seemed to be having such a good time. The NCA conferences I go to don't seem to be that much fun."

"Well Asilomar certainly was special. Whenever I think of that conference, I'm reminded of what Margaret Mead said about successful conferences-the intensity is so great you feel as if you're falling in love. The Asilomar conference was a love feast.

"What made it so special?"

"For many of us it was a turning point, or maybe I should say a turning-away point. Most of us thought of ourselves as social scientists but we also saw severe limitations in the positivist scientific tradition in which we'd been trained. We were searching for a different paradigm for communication research, something other than the quantitative, hypothesis-testing model that dominated."

"Weren't you aware of ethnography or cultural studies?"

"You have to understand that in the mid-1970s, there was no interpretive social science to speak of-at least not in communication studies. Students didn't do fieldwork for dissertations, they did laboratory experiments. There were no cultural approaches or cultural studies in communication, and the only ethnographic work that was encouraged was the narrowly focused ethnographies of speech communities (e.g., see Philipson, 1975).”

"How could you not have known?"

“Are you suggesting we weren't well educated?' I kid.

"No, but surely..."

"I guess it depends on what you mean by known or being aware," I interrupt. "Yes, we knew about phenomenology and existential psychology and some of us had read Wittgenstein (1953), Husserl (1931), and Charles Taylor (1971). We had studied the books by Erving Goffman $(1959 ; 1967)$ and Peter Berger and Thomas Luckmann (1966), and we knew about the field work originating in the Chicago School of symbolic interaction and the ethnographic tradition in anthropology on which Bateson's early research had been drawn (Bateson, 1937). But what I'm talking about is a sense of community--a group of scholars with a sense of a common purpose and common goals. There was no interpretive community in the field, no unified sense of purpose binding us together or giving us a sense of solidarity."

"I take it that's what you wanted to achieve at Asilomar, a feeling of community."

“To be honest, it really didn't start out that way. We knew Gregory Bateson was ill and those of us who admired his work wanted to honor his legacy while he still was alive. After all, he was the greatest communication theorist of our age. But once we started to make plans, we could see this event was going to be much bigger than 
we had thought. We had underestimated how many young and middle aged-scholars were desperately seeking an alternative to the Newtonian model of the academic."

"I noticed in the pictures that many of the speakers looked like hippies. Was this some kind of counterculture of inquiry?

“That's an interesting observation. A lot of the young scholars and graduate students who came were very much like Bateson-- unconventional, resistant to scientific orthodoxy, attracted to complexities of living beings, impatient with oversimplifications and de-contextualized knowledge, alienated by disciplinarity and careerism. Like Gregory, we felt ideas were just as important as data and we hungered for occasions to talk about the ideas that mattered most to us. Some of us had come through academia as members of the 60 s counterculture, but again, I'd have to say there was no unified culture, counter or otherwise."

"But if most of you were outside the mainstream, how were you able to get the funds to support the conference?"

"Getting all of us together at Asilomar was really a wild fantasy that Carol WilderMott turned into a dream come true. She somehow mustered support and endorsement from ICA's Interpersonal Communication Division, which had never been sympathetic to the sort of work represented by Batesonian communication theory. One thing led to another and before we knew it a hundred people were on the grounds in Pacific Grove, California. Most of the people who came had never seen or met Gregory Bateson and we couldn't wait to meet him. There was an air of excitement and expectation, a feeling that this was going to be an historic and memorable event."

"Do you think the conference had a lasting impact?" Leslie interrupts. "Did it make a difference in how students of communication think about what we do?"

I can't sit here and say that the conference changed the course of the field. Certainly it did not reverse the domination of Cartesian methodology in communication research. Even today most empiricists in the field cling tightly to the comforting illusion of detachment and objectivity. They ignore the brute fact that social scientists live in the same world they are trying to understand. We can never stand completely outside the phenomena we are studying. Bateson had no tolerance for experimental studies. "They strip away context," he would say, and "without context there is no communication, there is no meaning." This is such an obvious point, yet quantitative researchers, especially experimentalists, simply ignore it and go on with their meaning-less studies. The Asilomar conference had no effect on them.

"So the conference didn't matter all that much in the total scheme of things. Is that what you're saying?" Leslie persists.

“No, I wouldn't say that, Leslie. I came back from Asilomar very hopeful about the 
future of a relational and constructivist paradigm for communication research. I know others did too. It was the first time I sensed that a community of interpretive social scientists was emerging. I was astonished at how many people I met there wanted to study how people make sense of their lives, how communication contributes to sense making, and how we can use our research to help people live better lives. Not long after Asilomar we began to see a lot of interest surfacing in interpretive and qualitative approaches to communication research-work on organizational cultures and narratives, social construction, and personal narratives. Slowly but surely qualitative research gained momentum. When I was offered an opportunity to come to USF and develop an interpretive Ph.D. program emphasizing qualitative and ethnographic research, I jumped at it."

"I'm sure glad you did," Leslie says. "I don't know where I'd be without this program."

\section{Bateson on Observed Reality and Real Reality}

After Leslie leaves, I can't stop thinking about the Asilomar conference, about Bateson, and about her question: What difference did that conference make? I think about how rarely Bateson is cited in qualitative methods journals. He is never mentioned as a pioneering interpretive social scientist, and he is largely ignored in books that promote a "relational world view" (Gergen, 2009), though his work was instrumental in establishing the importance and usefulness of the idea of relationality.

I recall my first introduction to Bateson's writings in Raymond Tucker's graduate seminar on "Communication Theory" in which he slipped in two essays by Bateson (Bateson, 1951), "Information and Codification" and "Where Validity Depends Upon Belief," between Festinger's A Theory of Cognitive Dissonance (1962) and Thibaut and Kelly's The Social Psychology of Groups (1959). Bateson used the term "codification" to represent the perceptual processes by which we translate events or objects in the external world. External events are different from internal representations of those events, and codification expresses the way humans transform what is outside internally, that is, through the process of perceiving, categorizing and interpreting events and objects. We think that we think in terms of things, Bateson observed, but we actually think only in terms of relationships. "Our initial sensory data," he wrote (Ruesch and Bateson, 1951, p. 169) “are always 'first derivatives', statements about differences which exist among external objects or statements about changes which occur either in them or in our relationship to them...What we perceive easily is difference and change-and difference is a relationship." Bateson pointed out that when we don't recognize an object, or we're not sure about what we are seeing, we usually change our relationship to 
what we are viewing; we move closer to it, we touch it, or we do something to change our relationship to the object, giving us a different perspective on it. Our 'knowledge' is thus contingent on our positionality.

When we talk about knowing something, we implicate ourselves in what we claim to know. Observed reality is always something different from (real) reality because, in Bateson's terms, codification and valuation inevitably transform rather than copy reality. Since Bateson considered transformation to be mathematical, the representation of objective reality that results from all this is the product of an observer's internal computations, that is, the system of codification and evaluation. Since what is known has to be codified, what we actually perceive is the product of our perceptions rather than something we might call "objective reality." One could easily regard Bateson's essay as an early statement on what later became feminist"standpoint theory" (see Harding, 1991, 2004).

\section{Forming Warm Ideas}

I talked to Gregory Bateson face-to-face only on two occasions, once after a seminar he gave at the Temple University medical school in 1974, the other at the Asilomar conference in 1979, yet I regard him as the person who most influenced the direction and form of my life as a scholar and a teacher. At the Asilomar Conference, I delivered a paper titled "Forming Warm Ideas" (Bochner, 1981). My goal was to show how Batesonian communication theory resonated within me. By warm ideas I meant ideas that compel us to move closer to our subject matter, using ideas to extend inquiry into new territory and amplifying our understanding beyond what we knew before we started.

I emphasized three points about scientific practices: First, that scientific activity is recursive. To see phenomena a scientist must transform them; having transformed them, he or she is transformed by them; second, that data can not tell us what to ask of them, nor what they mean. Thus, the meanings of data are never beyond challenge, never closed to other meanings, never capable of absolutely falsifying or verifying. What we do to or with data is an intellectual activity; and third, ideas are as important as facts and nowhere is it evident that they are inducable from them. We need imagination not rules; intuition not technique; warm ideas not cold facts; inventive people not conformists, fertile thinking not rigid rules to follow.

If all humans operate on an external world they perceive as real-as the one and only world they know--then all attempts to "represent" reality are mediated attempts. Moreover, to represent reality is to link what is out there (objectively) to what is in 
here (subjectively). We take what we see with our eyes, grasp in our mind, and feel in our gut and we codify and express "it" in language. The rub is that the world does not exist in the shape of the sentences we write when we theorize or express what we see, what we think, and what we feel (Rorty, 1989). What we come to say about the world involves the indistinguishable provocations of the world-what is out there-and the mediations of codification and language by which we make claims about it (Bochner and Waugh, 1995). As Bateson (1977, p. 245) observed "somewhere between objectivity and subjectivity is a region where you are partly blown by the winds of reality and partly an artist creating a composite out of the inner and outer events."

Radical interpretivists like me are sometimes called names when we say things like this in mixed company. When we talk about knowledge as contextual and situated, of the necessity of multiple description, about how people "who see things from different points of view get tangled up in blue," as Bob Dylan put it, our polite friends call us "relativists" and our not so polite friends, the "methodological fundamentalists" discussed by Denzin (2009. p. 25), refer to us as "solipsists." Perhaps that is because they are afraid of subjectivity and jumpy about methodology. Our subjectivity is not a barrier between us and meaning, it is what makes meaning possible. Their resistance to our openness rests not on our subjectivism but on theirs. They can't see a way to fit our plot into the storyline they are accustomed to living. They think that if they work hard enough they will reach the one right interpretation. We think there can only be a good interpretation for certain purposes, and that interpretation always remains contestable and open to conversation. They are trying to end debate; we are trying to keep conversation going. Gregory Bateson liked to remind his readers that the solipsist is ultimately isolated and alone, confined by his premise that "I make it all up." But what about the opposite of solipsism? "There, at the other extreme, opposite solipsism, there is no choice because you could not possibly exist except as a metaphoric feather blown by the winds of external reality" (Brockman, 1977, p. 245).

At Asilomar, I took the liberty to transform how I had interpreted and come to understand a Batesonian perspective on social science inquiry into the following methodological guidelines (Bochner, 1981):

1. Study life in its natural setting, being careful not to destroy the historical and interactional integrity of the whole setting.

2. Think aesthetically. Visualize, analogize, compare. Look for patterns, configurations, figures in the rug.

3. Live with your data. Be a detective. Mull, contemplate, inspect. Think about, through, and beyond. 
4. Don't be controlled by dogmatic formalisms about how to theorize and conduct research. Avoid the dualisms pronounced by particularizing methodologists and theorist. They'll take their shots at you one way or the other anyhow.

5. Be as precise as possible, but don't close off possibilities. Look to the ever larger systems and configurations for your explanations.

6. Aim for catalytic conceptualizations; warm ideas are contagious.

\section{Three Decades Later}

Thirty years have passed since I wrote that paper. During the interim, many of us have moved at varying speeds away from modernist into postmodernist notions of social science. There is now a burgeoning interpretive and qualitative research community on an international scale. Although Gregory Bateson is not given much explicit credit for this transformation, he was saying long before this movement was set in motion that science is an ecology of mind in which the scientist lives in the same world of living things that he is seeking to understand. Whatever understanding we achieve is accomplished from inside as a participant within the processes of nature. No matter how hard we try to bracket our own participation in the processes of observation, we can never be outsiders. The idea of a detached and objective onlooker is an illusion. Referring to Bateson's path-clearing epistemology as "the charm of the scout," Stephen Toulmin (1981) regarded Bateson as an early prophet of postmodern science.

Now, thirty years later, I want to take this opportunity to extend Bateson's communicational world view to the international community of qualitative inquiry by specifying a few ideas I consider crucial to the interpretive social scientist's world view:

1. The first is what Gregory called "open epistemology," but which I call personal epistemology. It's the idea that we all live under the illusion that we are capable of direct, uncoded, un-mediated perception and experience. Bateson wrestled epistemology away from the confining clutches of philosophy and made it a part of natural history. To understand human communication we have to grant the limits of our own sensory capabilities. Everyone operates on the world. You do. I do. We all do. And none of us knows precisely how. As I mentioned above, Bateson showed that we only perceive the product of our perceptions, not the means by which the product is generated.

We have yet to take seriously the consequences of mediated perception and experience. I am my own epistemology. I operate on the world from the perspective of an inner world constituted in that epistemology. Thus, whatever I call "truth" has to be akin not so much to what I perceive as to how I perceive, that is, the process of 
perception. How I learn is who I am and what I know. Epistemology is personal because it's a product of my senses-what I can see, touch, and feel-and that's all I can know. Ironically, all we can ever understand is organized by our epistemology, yet we are blinded by the light. All of us have a blind spot; we don't know how we see or understand. When we grasp the significance of open epistemology we get much closer to a recursive, reflexive orientation, and to recognizing the limits of lineal thinking.

2. The enduring search for the how. From the beginning of his work as an anthropologist in New Guinea (Bateson, 1937) to the later work on adaptation, addiction, and difference, Bateson always searched for process answers. Often his work begins with one typology or another, but Bateson was quick to say that taxonomies and typologies are only way stations. As he put it, "The way to phrase scientific questions is with the word "how" and not with the word "why." If one is interested in classifying persons or cultures, then one looks for the processes of interaction between persons that produced those differences in types.

3. Layers and relationships. Life is organized and organized life occurs in layers. We have messages, and messages about messages, and messages about messages about messages; ideas and ideas about ideas; contexts and contexts of contexts; learning and learning to learn; levels of learning, levels of context, levels of communicating; messages and meta-messages and meta-meta-messages. Interactional life is deeply embedded in issues and problems of classification and fraught with the many difficulties and potentially catastrophic consequences of classification errors. To grant and understand the layered quality of organized life is to recognize the connections and patterns between the layers--connections, bridges, linkages, relationships. Perhaps the biggest danger is the illusion of self-contained individualism--the perils of not recognizing the realities of relatedness and interdependence. Every classification, every individual, every part is defined by its relation to the others. As qualitative researchers, we resist the hegemony of experimental, quantitative, evidence-based, and positivistic social science, yet the foundation of our identity is formed in relation to these Others. Denzin (2009) speaks of "fighting back," of feeling "under fire" and of the "disputes" and "conflicts" with the scientifically based research (SBR) movement that have inspired the new paradigms of social justice and activist qualitative research. These differences make a difference. Our relation to these Others fuels our passions, helps us define our mission, and gives us perspective on who we are and what we want. We get in trouble, however, when we think the differences between "them" and "us" is something akin to a problem to be solved. It isn't. As Rorty said, "these are not problems to be solved but differences to be lived with." We ought to be asking not "how can we change their perception of us" but how can we learn to live together and appreciate the differences 
between us. The issue is not whether they are right or we are right-we both think we are-but rather is the world of inquiry large enough to accommodate both of our interests? Aren't there legitimate goals on both sides of the divide?

4. This brings me to framing, which is the final point I want to introduce into this discussion. Bateson saw that the concept of a message framed by another message could not only lead to confusion but to error. The idea of a framing message implied a hierarchy of messages in which it appeared that one level of a message was of a higher order than another and that messages were confined to two levels, one of which was meta to the other. But in face-to-face human communication, when we are trying to figure out whether a message is meant as playful, ironic, teasing, or intentionally hurtful, we are confronted simultaneously with verbal, visual, and vocal messages as well as with the context of our encounter. In these cases, there is no message per se, only meta-messages qualifying each other in ways that could be interpreted as congruent, incongruent, or conflictful.

I doubt if there is a more fertile idea in communication theory than the idea of framing. In Bateson's lecture at Asilomar, he said, "epistemological errors are part of the machinery of the descent into hell." He was trying to get us to understand that the nature of pattern in the natural world is not something to take lightly or to fool around with and if we don't respect the natural order of interdependencies we can end up disrupting the balances. The results can be toxic and monstrous. I end this article with a story that puts into perspective just how serious these ideas can be. In the events on which this story is based, I witnessed how catastrophic the consequences of a framing error could be.

\section{Chilling Consequences of Epistemological Error}

In the summer of 1985, shortly after I became chair of the Department of Communication at the University of South Florida, I attended an orientation meeting for administrators and administrative assistants. About an hour into the meeting, a faculty member in my department interrupted to tell me that Ginny Bulger, a 50 year old, petite woman, who had been a secretary in the department for more than a decade, had not returned to work after lunch. Normally, this would not have been worrisome, but Ginny was a very punctual person who followed set routines each day. It was now nearly 2:30 and nobody had heard from her. When her car was located in its normal place in the building's parking lot, under the shade tree where she always parked, we became increasingly alarmed. Over the next several hours, concern turned to distress, then to dread. Ginny lived with her 75 year-old mother whom she called several times 
a day. When we contacted her, she told us she had not heard from Ginny since before lunch. After we searched classrooms, faculty offices, and rest rooms in the building for more than two hours, our worst fears were confirmed. At around 5:00 p.m., I discovered Ginny's body in a locked classroom in the rear of our office complex. She was laying naked on the floor, face up, her legs spread apart, and her panties tied tightly around her neck. Later it was determined that she had died several hours earlier.

Panic, terror, and grief circulated chaotically through Cooper Hall as the City of Tampa police detectives made their way to the crime scene to begin an investigation. After several grueling hours of police questioning, most of us left the building still in a state of shock and without an inkling of the details of the events surrounding Ginny's death. Later that night I was told by the detective in charge of the case that Ginny had been raped and murdered probably around 1:00 in the afternoon and there were no suspects and no leads. Except for an implausible twist of fate, it is unlikely that Ginny's murderer would ever have been discovered. Here is what happened:

At about the same time I began to read the newspaper accounts of Ginny's murder-the next morning-three male engineering students were receiving the same news. But their perspective was entirely different from mine. They could have prevented Ginny's murder, but they didn't. I can only imagine how shocking it must have been when they realized what a colossal mistake they had made.

At the trial several months later each boy told his own version of the same story. The seminar room in the back hallway was a place that the engineering students often used as a study room when it wasn't occupied. The three of them had walked up the fourth floor expecting to use the room to study for their final exam in an engineering course. When they got there, the door was closed and locked. One of them had walked a bit ahead of the others. When he found the door locked, he stood on his toes and peeked in the single narrow window near the top of the door. There he saw what he described as a fully-dressed white male holding a pair of woman's panties in his hand and kneeling over a naked woman. He recognized the man in the room as a fellow engineering student who was in one of his classes. Almost immediately he turned to his two friends and said, "You have to see this to believe it. Wow, it's a couple of co-eds making whoopee in the middle of the afternoon." In turn each of his two friends took a quick glance into the room, each shaking his head in disbelief. Neither questioned the interpretation of the first guy. They thought they were witnessing risqué sex. Not wanting to interrupt the party, one of the men suggested that they go to the second floor to study and the three of them left the scene. At the trial, the coroner reported the results of an autopsy that showed Ginny had been knocked unconscious but was still alive at the time these three men peeped into the room. They could have saved her life had it not been for their profound epistemological 
error. We can only theorize about what made them abstract the signals they witnessed into the frame of risqué sex and not into the frame of rape and/or murder. They never questioned their assumptions, never considered the possibility that some darker scene was being played out, never suspected that a fully dressed male standing over a naked woman could have been a rapist rather than a lover.

At Asilomar Gregory Bateson ended his talk by recalling a quotation from one of the Nazis at Nuremberg who had been asked "Did you know what was happening in the death camps?" "No, I did not know," he replied, "but I could have known." For the past twenty-four years, every time I recall what happened that day I am reminded that those three boys didn't know. Then, I hear a voice, wavering between anger and sadness, whispering in my ear, "Surely they could have known, surely they could have."

\section{Acknowledgment}

The author acknowledges the assistance of Carolyn Ellis whose keen eye and thoughtful commentary contributed significantly to this project.

\section{References}

Bateson, G. (1937). Naven. Cambridge: Cambridge University Press.

Bateson, G. (1951). Information and codification: A philosophical approach. In J. Ruesch \& G. Bateson (Eds.) Communication: The social matrix of psychiatry (pp. 168-211). New York: Norton.

Bateson, G. (1951). Conventions of communication: Where validity depends upon belief. In J

Ruesch \& G. Bateson (Eds.) Communication: The social matrix of psychiatry. (pp. 212-227). New York: Norton.

Bateson, G. (1972). Steps to an ecology of mind. New York: Ballentine Books.

Bateson, G. (1977). Afterward. In J. Brockman (Ed.) About Bateson (pp. 235-247) New York: Dutton.

Bateson, G. (1981). Paradigmatic conservatism. In C. Wilder Mott \& J. Weakland (eds.) Essays from the Legacy of Gregory Bateson (pp. 347-355). Palo Alto, Ca.: Praeger.

Berger, P. \& Luckmann, T. (1967). The social construction of reality: A treatise in the sociology of knowledge. New York: Anchor Books.

Brockman, J. (Ed.) (1977). About Bateson. New York: Dutton.

Bochner, A. (1981). Forming warm ideas. In C. Wilder-Mott and J. Weakland. (eds.) Rigor and Imagination: Essays from the Legacy of Gregory Bateson, (pp. 65-81). Palo Alto, Ca.: Praeger.

Bochner, A. \& Waugh, J. (1995). Talking-with as a model for writing about: Implications of Rortian pragmatism for communication Theory. In L. Langsdorf and A. Smith (Eds.) Recovering pragmatism's voice: The classical tradition and the philosophy of communication (pp. 211-233). New York: SUNY Press. 
Denzin, N. (2009). Qualitative inquiry under fire: Toward a new paradigm dialogue. Walnut

Creek, Ca.: Left Coast Press.

Festinger, L. (1957). A theory of cognitive dissonance. Evanston, Ill.: Row, Peterson.

Gergen, K. (2009). Relational being: Beyond self and community. New York: Oxford University

Press.

Goffman, E. (1959). The presentation of self in everyday life. Garden City, N.Y.: Anchor.

Goffman, E. (1967). Interaction ritual: Essays on face-to-face behavior. Garden City, N.Y.: Anchor.

Haley, J. (1963). Strategies of psychotherapy. New York: Grune and Stratton.

Husserl, E. (1931). Ideas: A general introduction to pure phenomenology, 1913. (W. R. Boyce

Gibson, Trans.). New York: Humanities Press.

Harding, S. (1991). Whose science? Whose knowledge? Thinking from women's lives. Ithaca,

New York: Cornell University Press.

Harding, S. (Ed.) (2004). The feminist standpoint theory reader. New York: Routledge.

Philipsen, G. (1975). Speaking 'like a man' in Teamsterville: Culture patterns of role enactment in an urban neighborhood. Quarterly Journal of Speech (61) pp.13-22.

Rorty, R. (1989). Contingency, irony, and solidarity. Cambridge: University of Cambridge Press.

Rorty, R. (1991). Objectivity, relativism and truth: Philosophical papers, Volume I. Cambridge:

University of Cambridge Press.

Taylor, C. (1971). Interpretation and the sciences of man, Review of Metaphysics, (25) pp. 3-51.

Thibaut, J. \& Kelley, H. (1959). The social psychology of groups. New York: Wiley.

Wilder-Mott, C. \& Weakland, J. (Eds.) (1981). Rigor and imagination: Essays from the legacy of Gregory Bateson. Palo Alto, Ca.: Praeger.

Wittgenstein, L. (1953). Philosophical investigations. (Trans. G. Anscombe). New York: Macmillan.

\section{About the Author}

Arthur P. Bochner is Distinguished Professor of Communication at the University of South Florida. In 2008, he served as the President of the National Communication Association (NCA). He is the author of more than 80 published articles and chapters and co-editor of the Left Coast Book Series "Writing Lives: Ethnographic Narratives." Portions of this article are taken from A. Bochner, Tales Out of School: Meaning and Method in a University Life, Left Coast Press (forthcoming). 